\title{
Características físico-químicas do leite pasteurizado, dos tipos B e $C$, processado por sete usinas de beneficiamento do Estado de São Paulo
}

\section{Physico-chemical characteristics of pasteurized milk, types B and C, processed by seven milk factories in the State of São Paulo, Brazil}

\author{
Antonio Nader Filho, Luis Augusto do Amaral, Oswaldo Durival Rossi Júnior
}

\begin{abstract}
Resumo
Foram submetidas às determinações de acidez, densidade, teor de gordura, extrato seco total e extrato seco desengordurado 32 amostras de leite pasteurizado do tipo $\mathrm{B}$ e 80 do tipo $\mathrm{C}$ colhidas em sete usinas de beneficiamento do Estado de São Paulo. Os resultados obtidos evidenciaram que cinco (15,6\%) amostras do tipo B e oito (10\%) do tipo $\mathrm{C}$ apresentaram-se fora dos padrões físico-químicos estabelecidos pelo Ministério da Agricultura.
\end{abstract}

Palavras chave: leite; leite pasteurizado tipo B; leite pasteurizado tipo C; características físico-químicas

\section{Introdução}

Os trabalhos desenvolvidos para avaliar a composição físico-química dos diferentes tipos de leite pasteurizado distribuídos ao consumo têm evidenciado a ocorrência de elevado número de amostras fora dos padrões legais.

Silveira et al. (1988) e Nader Filho et al. (1992) examinando o leite pasteurizado comercializado nas cidades de São Paulo e de Ribeirão Preto, no Estado de São Paulo, verificaram que $84,5 \%$ e $15,9 \%$ das amostras do tipo B e $18,1 \%$ e $9,1 \%$ do tipo C, apresentavam-se fora dos padrões físico-químicos estabelecidos pelo Ministério da Agricultura.

Tais achados têm sido atribuídos à provável ocorrência de fraudes ou falsificações do produto (Silveira et al., 1988) e a fatores nutricionais e ambientais que podem influenciar a produção dos rebanhos leiteiros, especialmente durante os períodos de entressafra (Santos et al.,1981; Rossi Júnior et al., 1982).

Diante do exposto e considerando a necessidade de informações complementares que permitam melhor avaliar a qualidade dos diferentes tipos de leite pasteurizado distribuídos ao consumo, realizou-se o presente trabalho com o objetivo de conhecer as características físico-quí- micas do leite pasteurizado, dos tipos $B$ e $C$, processado por sete usinas de beneficiamento do Estado de São Paulo.

\section{Material e Métodos}

Durante o período de maio de 1994 a agosto de 1995, foram colhidas 32 amostras de leite pasteurizado do tipo $B$ em duas usinas de beneficiamento e 80 do tipo $C$ em outras cinco, situadas no Estado de São Paulo e subordinadas à fiscalização do Serviço de Inspeção Federal.

Assim, mensalmente, logo após o envase em embalagens plásticas comerciais com $1000 \mathrm{ml}$, foram colhidas as amostras do leite pasteurizado. Após o acondicionamento em caixas de isopor contendo cubos de gelo, as amostras foram transportadas para os laboratórios do Departamento de Medicina Veterinária Preventiva da Faculdade de Ciências Agrárias e Veterinárias, "Campus de Jaboticabal", da Universidade do Estado de São Paulo para a realização das análises físico-químicas.

As referidas análises, que foram efetuadas de acordo com as técnicas propostas pelo Ministério da Agricultura (1981), envolviam as determinações de acidez Dornic, densidade, teor de gordura, extrato seco total e extrato seco desengordurado.

\section{Resultados e Discussão}

A Tabela 1 mostra a distribuição dos valores médios das análises físico-químicas de 32 amostras de leite pasteurizado do tipo $\mathrm{B}$ e de 80 do tipo $\mathrm{C}$, colhidas em algumas usinas de beneficiamento Estado de São Paulo. As amostras do tipo $B$ apresentaram valores médios ligeiramente superiores às do tipo $\mathrm{C}$ no teor de gordura $(3,5 \%)$ e no extrato seco total $(12,6 \%)$. Por outro lado, as do tipo $\mathrm{C}$ evidenciaram valores médios ligeiramente superiores às do tipo $B$ na acidez Dornic $\left(16^{\circ} \mathrm{D}\right)$, na densidade $(1,0324)$ e no extrato seco desengordurado $(9 \%)$.

Os dados da Tabela 1, quando comparados com os 
Tabela 1 - Valores médios das análises físico-químicas de 32 amostras de leite pasteurizado tipo $\mathrm{B}$ e de 80 tipo $\mathrm{C}$, colhidas em algumas usinas de beneficiamento do Estado de São Paulo (1994/1995)

\begin{tabular}{lcc}
\hline \multirow{2}{*}{ Análises } & \multicolumn{2}{c}{ Leite pasteurizado } \\
\cline { 2 - 3 } físico-químicas & Tipo B & Tipo C \\
\hline Acidez $\left({ }^{\circ} \mathrm{D}\right)$ & 15,6 & 16 \\
Densidade & 1,0319 & 1,0324 \\
Teor de gordura $(\%)$ & 3,5 & 3,4 \\
EST $(\%)$ & 12,5 & 12,4 \\
ESD $(\%)$ & 8,9 & 9 \\
\hline
\end{tabular}

EST: extrato seco total; ESD: extrato seco desengordurado

obtidos por Nader Filho et al. (1992) em amostras de leite pasteurizado do tipo $B$ colhidas no comércio varejista de Ribeirão Preto, mostraram-se ligeiramente inferiores nas determinações de acidez Dornic, teor de gordura, extrato seco total e extrato seco desengordurado, porém, idênticos quanto à densidade, com valores de $16,4^{\circ} \mathrm{D}, 3,9 \%$, $12,9 \%, 9 \%$ e 1.0319 , respectivamente. Por outro lado, quando comparados com os dados obtidos pelos referidos autores em amostras do tipo $\mathrm{C}$, mostraram-se ligeiramente superiores no teor de gordura e no extrato seco total, porém idênticos na densidade e ligeiramente inferiores na acidez Dornic e no extrato seco desengordurado, com valores de $3,2 \%, 12,2 \%, 1,0324,16,6^{\circ} \mathrm{D}$ e $9 \%$, respectivamente.

A Tabela 2 mostra a distribuição das amostras de leite pasteurizado, dos tipos $\mathrm{B}$ e $\mathrm{C}$, em algumas usinas de beneficiamento do Estado de São Paulo, fora dos padrões estabelecidos pelo Ministério da Agricultura. Os dados evidenciam que três $(9,4 \%)$, quatro $(12,5 \%)$ e uma $(3,1 \%)$ amostras do tipo B apresentaram-se fora dos padrões estabelecidos para teor de gordura, extrato seco total e extrato seco desengordurado. Por outro lado, mostram que duas $(2,5 \%)$, duas $(2,5 \%)$, quatro $(5 \%)$, quatro $(5 \%)$ e

Tabela 2 - Distribuição de 32 amostras de leite pasteurizado tipo $\mathrm{B}$ e de 80 tipo $\mathrm{C}$, colhidas em algumas usinas de beneficiamento do Estado de São Paulo, fora dos padrões estabelecidos pelo Ministério da Agricultura, segundo as análises físico-químicas (1994/1995)

\begin{tabular}{|c|c|c|c|c|}
\hline \multirow{3}{*}{$\begin{array}{l}\text { Análises } \\
\text { físico-químicas }\end{array}$} & \multicolumn{4}{|c|}{ Leite pasteurizado } \\
\hline & \multicolumn{2}{|c|}{ Tipo B } & \multicolumn{2}{|c|}{ Tipo $\mathrm{C}$} \\
\hline & № & $\%$ & № & $\%$ \\
\hline Acidez ( $\left({ }^{\circ}\right)$ & - & - & 2 & 2,5 \\
\hline Densidade & - & - & 2 & 2,5 \\
\hline Teor de gordura (\%) & 3 & 9,4 & 4 & 5 \\
\hline EST $(\%)$ & 4 & 12,5 & 4 & 5 \\
\hline ESD $(\%)$ & 1 & 3,1 & 3 & 3,7 \\
\hline Total & 8 & 15,6 & 15 & 10 \\
\hline
\end{tabular}

EST: extrato seco total; ESD: extrato seco desengordurado três $(3,7 \%)$ do tipo C, apresentaram-se fora dos padrões estabelecidos para acidez Dornic, densidade, teor de gordura, extrato seco total e extrato seco desengordurado, respectivamente.

Os dados da Tabela 2 revelam ainda que cinco $(15,6 \%)$ amostras do tipo B e oito (10\%) do tipo C, apresentaramse fora dos padrões físico-químicos estabelecidos pelo Ministério da Agricultura.

Silveira et al. (1988) e Nader Filho et al. (1992), analisando amostras de diferentes tipos de leite pasteurizado comercializados nas cidades de São Paulo e de Ribeirão Preto verificaram que $84,5 \%$ e $15,9 \%$ das amostras de leite do tipo B e 18,1\% e 9,1\% do tipo C, apresentaram-se fora dos referidos padrões legais.

Os achados do presente trabalho evidenciam que as amostras de leite pasteurizado, dos tipos $\mathrm{B}$ e $\mathrm{C}$, apresentaram qualidades semelhantes às verificadas por Nader Filho et al. (1992), porém superiores às observadas por Silveira et al. (1988).

Especial atenção deve ser dispensada à concentração de amostras fora dos padrões regulamentares entre os meses de junho, julho e agosto, ou seja, durante os meses que caracterizam o período das secas. Huber e Bonan (1966), Loganathan e Thompson (1968) e Rossi Junior et al. (1982) observaram variações semelhantes que os levaram a acreditar na provável interferência de fatores nutricionais e ambientais. Assim, conclui-se que é necessário intensificar a fiscalização para atenuar as prováveis interferências dos fatores nutricionais do rebanho sobre a qualidade físico-química dos diferentes tipos de leite.

\section{Abstract}

Physico-chemical characteristics of pasteurized milk, types $B$ and $C$, processed by seven milk factories in the State of São Paulo, Brazil

The examination of 32 milk samples type $B$ and 80 type $C$ was carried out to determine the acidity, the density, the fat percentage, the total dry matter and the skimed dry matter. The samples were collected in seven milk factories, in the State of São Paulo, Brazil. The results showed that five (15.6\%) milk samples B type, and eight (10\%) C type were out of the physical and chemical standards established by the Ministry of Agriculture.

Key words: milk; pasteurized milk type B; pasteurized milk type $\mathrm{C}$; physical chemical characteristics

\section{Referências bibliográficas}

Huber JT, Bonan RL 1966. Nutritional factors affecting the solid-non-fat content of milk. J Dairy Sci 49:816-821.

Loganatham S, Thompson NR 1968. Composition of cow's milk. 1 - Environmental and managerial influences. J Dairy Sci 51 : 1928-1932. 
Ministério da Agricultura 1981. Métodos analíticos oficiais para controle de produtos de nrigem animal e seus ingredientes. Métodos Físico-Químicos, Brasilia, DF.

Nader Filho A, Amaral LA, Rossi Júnior OD, Freitas Luiz AF 1992. Características físico-químicas do leite pasteurizado dos tipos A, B e C comercializados na cidade de Ribeirão Preto, Estado de São Paulo. Arq Bras Med Vet Zootec 44(2): 145-150

Rossi Júnior OD, Nader Filho A, Faleiros RR, Lopes JL, Schocken-Iturrino RP 1982. Análises das condições físicoquímicas e bacteriológicas do leite oferecido ao comércio varejista de Jaboticabal/SP. Rev Inst Lactic Cândido Tostes 220: 15-19.

Santos EC, Genigeorgis C, Farver TB 1981. Prevalence of S. aureus in raw and pasteurized milk used for commercial manufacturing of Brasilian Minas Cheese. J Food Prot 44: $172-176$

Silveira NVV, Sakuma H, Duarte M, Rodas MAB, Saruwatarin JH, Chicourel EL 1988 . Avaliação das condições físicoquímicas e microbiológcias do leite pasteurizado consumido na cidade de São Paulo. Rev Inst Lactic Cândido Tostes 260: 40-45. 